\title{
ATLANTO-AXIAL FRACTURE-DISLOCATION
}

\section{Report of a Case}

\section{G. O. Tippett, London, England}

A stockily built man of fifty-eight years was thrown from his horse in December 1947 and landed heavily on the right side of his face. He was dazed for a few seconds but on recovering he noticed pain and "pins and needles" radiating down both arms and inability to move the upper or lower extremities. After a few minutes the pain and tingling disappeared, movement returned in the arms and legs and the patient then was conscious of intense pain in his neck, partly relieved by supporting his chin with his hands. Radiographs were deceptive and he was thought to have sustained a simple contusion. Later in the day he had some difficulty in swallowing, which increased until food and drink were regurgitated through the nose. Speech became thick and nasal and there was a feeling of obstruction to breathing which

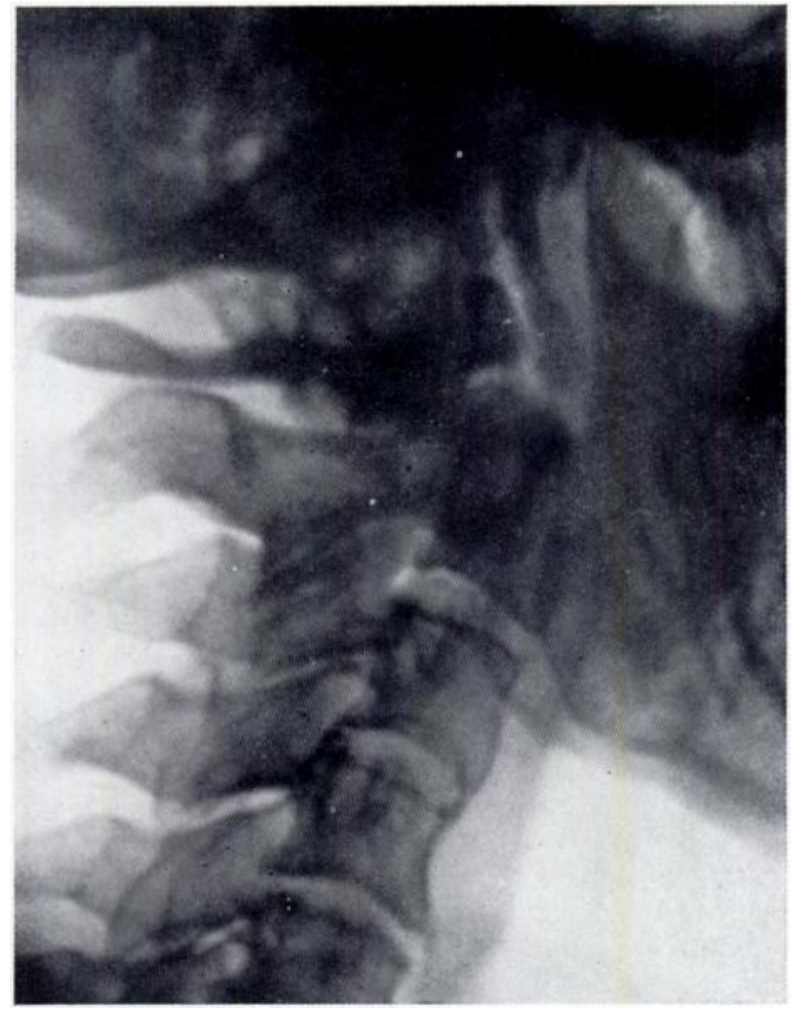

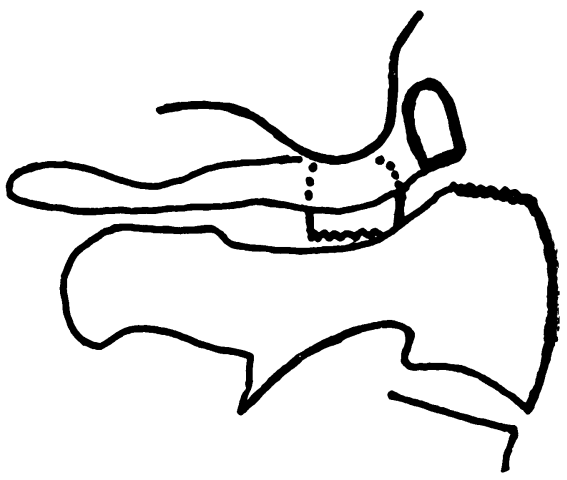

FIG. 2

Figure 1-Radiograph of the cervical spine taken shortly after the injury. Note fracture through the base of the odontoid process. The atlas vertebra, carrying with it the odontoid peg and the occiput, has been displaced markedly backwards. Figure 2 is a tracing from the radiograph.

FIG. 1

greatly alarmed the patient. The sense of taste was lost. The left occipital part of the scalp became so sensitive that he could not brush his hair and there was severe and persistent neuralgia over the whole occipital region.

Examination showed considerable swelling and tenderness over the upper part of the neck; gross restriction of neck movements, the head being held rigidly in extension and the chin supported by the hands; swelling of the back of the pharynx and paralysis of the left side of 
the soft palate; irregularity of the posterior pharyngeal wall palpable through the mouth; and marked hyperaesthesia of the occipital region of the scalp. There were no motor, sensory or reflex abnormalities in the arms or legs.

Radiographs (Fig. 1) disclosed: 1) fractures of the anterior arch and right lateral mass of the atlas; 2) a fracture through the base of the odontoid process; 3 ) backward displacement of the odontoid, the atlas and the skull in relation to the axis; 4) osteoarthritis of the mid-cervical spine.

Treatment-A plaster-of-Paris jacket of the "Minerva" type was applied without an anaesthetic after the head had been gently coaxed from the extended to the neutral position. It was felt undesirable to attempt accurate reduction lest the cord be damaged in the process. Much difficulty was encountered in making the patient comfortable because the hyperaesthesia and the occipital neuralgia made a closely fitting collar intolerable. Nevertheless, moderately effective immobilisation in a collar was maintained for three months. Six months after the accident there was a fair range of painless movement, speech and swallowing were normal, and there were only transient pains in the occipital region. Three years after the accident the patient wrote as follows: "The movements of my neck have loosened up considerably, though there is still a certain limitation to the freedom of my movement. I started swimming nine months after the accident and riding a little later. The tenderness of the scalp was the thing that troubled me longer than anything else. Now it sometimes returns, but only in connection with headaches I derive from colds or overwork."

Comment-Atlanto-axial fracture-dislocation is an uncommon injury (Crooks and Birkett 1944) which has been well described by Jefferson $(1920,1927)$ and by Plaut (1938). It is not accompanied by severe involvement of the cord or by death as frequently as is dislocation of the atlas on the axis without a fracture of the odontoid. The present case is an example of an injury produced by hyperextension which, in people of this age group with cervical osteoarthritis, can have even more serious consequences (Barnes 1948).

In addition to the clinical picture which characterises fractures and fracture-dislocation of the cervical spine, atlanto-axial fracture-dislocations present special signs occasioned by certain anatomical relationships. Thus there may be severe occipital neuralgia and hyperaesthesia of the back of the scalp due to involvement of the great and sub-occipital nerves which are intimately related to the postero-lateral arches of the atlas. Secondly, there may be dysphagia and alterations in speech and taste due to tearing and bruising of the constrictor muscles of the pharynx and injury to the corda tympani, glossopharyngeal and palatal nerves. It is important to be aware of these classical signs of the injury, for radiographs of the occipito-cervical region may be obscured by the mastoid air cells and are often difficult to interpret unless stereoscopic views or tomograms are available.

\section{REFERENCES}

Akerman, J. (1932): Acta Chirurgica Scandinavica, 71, 23.

Barnes, R. (1948): Paraplegia in Cervical Spine Injuries. Journal of Bone and Joint Surgery, 30-B, 234. Crooks, F., and Birketr, A. N. (1944): Fractures and Dislocations of the Cervical Spine. British Journal of Surgery, 31, 252.

HAMBLY, E. H. T. (1944): Lancet, ii, 851.

JefFerson, G. (1920): Fracture of Atlas Vertebra. British Journal of Surgery, 7, 407.

Jefferson, G. (1927): British Medical Journal, ii, 153.

Jefferson, G. (1940): Proceedings of the Royal Society of Medicine (Section of Orthopaedics), 33, 657.

Plaut, H. F. (1938): American Journal of Roentgenology, 40, 867. 